\title{
Citrus Fruit Peels in Combating Various Foodborne Pathogens
}

\author{
Aziz Fatima*, Maham Ghouri and Toba Sajid \\ Jinnah University for Women, Karachi, Pakistan
}

\section{ABSTRACT}

Foodborne diseases are the world's main problem in a society nowadays; many phytochemicals are of great interest to scientists. Herbal medicines can be used to treat many infectious diseases. In our study, we focus on screening of antibacterial activity of the lemon (Citrus limon) and orange (Citrus sinesis) peels against various pathogens. Bioactive compounds have been found in variety of citrus fruits that have favorable impact on human health. The major component; flavonoids have been found in the peels of citrus fruits in large amount. Citrus peel has a rich amount of flavonoid and other poly methylated flavonoids (exceptional to some plants). These antibacterial compounds exhibit antibacterial activity and have wide application in both food and pharmaceuticals industries. The citrus peel extracts show effective antimicrobial activity. The antagonistic activity of selected citrus peel extracts was determined by agar well diffusion; against test organisms i.e. Escherichia coli, Salmonella typhi and Bacillus subtilis isolated from food products. Effectiveness of peel extracts are measured in terms of inhibitory zones in millimeter. The methanol extract of lemon peel displayed zone of inhibition in between $5 \mathrm{~mm}$ to $8 \mathrm{~mm}$ and methanol extract of orange peel displayed zone of inhibition about $10 \mathrm{~mm}$ and $11 \mathrm{~mm}$. It was observed that lemon peel extract has maximum antibacterial activity against Bacillus subtilis $(8 \mathrm{~mm})$ and minimum antibacterial activity against Salmonella typhi $(5 \mathrm{~mm})$ whereas orange peel extract has maximum antibacterial activity against Bacillus subtilis $(11 \mathrm{~mm})$ and minimum antibacterial activity against Salmonella typhi $(10 \mathrm{~mm})$. Both Citrus peels extract showed considerable antibacterial activity against all tested foodborne pathogens. Our main focus was the use of herbal treatments against various infections which overcome the emergence of upcoming superbugs.

Keywords

Citrus peel, antimicrobial activity, foodborne pathogens, flavonoids, agar well diffusion.

Cite this article: Fatima $A$, Ghouri $M$, Sajid T. Citrus Fruit Peels in Combating Various Foodborne Pathogens. RADS J. Biol. Res. Appl. Sci. 2018; 9(2): 64-66.

This is an Open Access article distributed under the terms of the Creative Commons Attribution License (http://creativecommons.org/licenses/by/4.0), which permits unrestricted use, distribution, and reproduction in any medium, provided the original work is properly cited.

\section{INTRODUCTION}

The resistance of microbes has been increased due to extensive use of antimicrobial drugs. These organisms have various gene pools that carry such genes which have ability to acquire resistance from adjacent organisms ${ }^{1}$. In previous studies, plants and other natural sources are considered as vital agents' natural compounds that have been used to cure many health- related issues ${ }^{2}$. The extracts of such medicinal plants can contribute a lot at industrial level especially in pharmaceuticals, due to their antibacterial properties ${ }^{3}$. Among these plants, the products of citrus fruits have shown effective inhibitory activity against pathogenic bacteria. Lemon and orange are important in relation to medicine, belongs to the family Rutaceae (citrus family). 
These are the compounds which have potent bioactive component that have provided beneficial effect on human health such as vitamins, flavonoid, minerals, and alkaloids. Flavonoids extracted from Citrus peels have shown high spectrum of bactericidal, fungicidal activity along with, antidiabetic, anticancer and antiviral activities ${ }^{4,6}$. These bioactive components can act as free radical scavengers and are also capable to control different enzymatic reactions and inhibit cell progression. Extracts of citrus peels have also shown the activity against phytopathogens ${ }^{5,7}$. The research study was design off to evaluate the inhibitory effect of peel extract of two citrus fruits namely lemon (Citrus limon) and orange (Citrus sinesis) peels against food borne pathogens.

\section{MATERIAL AND METHOD}

\section{Extract Preparation Bacterial Isolates}

Microbes were isolated from different food products and identified using standard protocols. Cultures were stored and maintained for screening antibacterial activity.

The fruits were properly washed with distilled water for about 2 or 3 times. Fruit peels were then separated, shredded into small pieces, dried in shaded area and then a fine powder were made. Twenty-five grams of peel powder was then added into separate flask, mixed with $100 \mathrm{ml}$ of methanol and kept for 24 hours. Flask content was then filtered by using sterile what man filter paper as prescribed and allowed to dry by evaporation. Condensed peel extract was then used for screening the bactericidal potential.

\section{Collection of Citrus Fruits}

The ripe citrus fruits (orange and lemon) were collected from supermarket of Karachi.

\section{Agar Well Diffusion Assay}

24 hours old prepared nutrient broth inoculated with test organisms was matched to $0.5 \mathrm{McF}$ arland tube. Twentyfive $\mathrm{ml}$ of MHA was poured in labeled petri plates, test organisms were aseptically streaked on surface of sterile Muller-Hinton agar surface, followed by formation of agar wells of $10 \mathrm{~mm}$ diameter using a sterile borer. An amount of $0.5 \mathrm{ml}$ of extract was then poured in respective wells. Tetracycline disc was used as positive control. Plates were then kept incubated for 1 day at $37^{\circ} \mathrm{C}$. Zone of inhibition were then measured around the agar well.

\section{RESULTS \& DISCUSSIONS}

Antimicrobial activity of orange peel and lemon peel was assessed against the above-mentioned foodborne pathogens using agar well diffusion technique. The results are presented in Fig. 1-4.

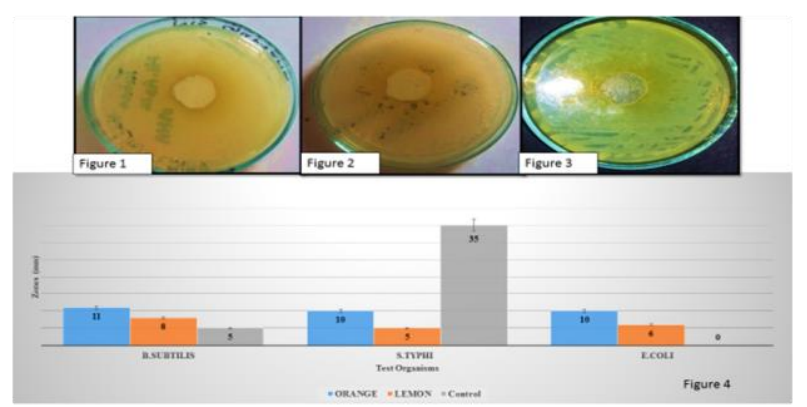

Fig. 1, 2 and 3: represent the inhibitory effects on E. coli, $S$. typhi and $B$. subtilis respectively. Fig. 4: shows graphs of orange and lemon peels against test organisms.

According to our findings, Orange peel showed excellent inhibition against all the test organisms showing the highest zone of inhibition against $B$. subtilis, S. typhi and E. coli. Orange peel thus showed a broad spectrum activity against all the selected foodborne isolates screened in this research study. On the other hand, Lemon peel showed inhibition against all the test organisms with a maximum zone of inhibition against $B$. subtilis and minimum zone of inhibition against $S$. typhi whereas control i.e. tetracycline inhibits $S$. typhi, $B$. subtilis and $E$. coli shows resistance to tetracycline. We then compared result of this with the previous studies. Demonstration with antibacterial activity of commonly available fruitpeels ${ }^{8}$ showed similar results as revealed in present study i.e. citrus peel extract of orange fruit showed with an inhibitory zone size of $11-12 \mathrm{~mm}$ against Bacillus subtilus. Whereas $S$. typhi and $E$. coli were found resistant against both peel extract than the current study in which we found zone of inhibition 5-10 mm in lemon and orange peel respectively in case of $S$. typhi and $6-10 \mathrm{~mm}$ zone of inhibition in lemon and orange peel respectively in E. coli.

It has been experimentally shown that in our study peel extracts of citrus fruit inhibit microbial growth. Similar to 
the study conducted in 2009. They evaluated bactericidal potential of peel oil using citrus fruits. It was found in the study that citrus plant including, Citrus sinesis and Citrus limon exhibit antibacterial activity against their test organisms or bacterial isolates.

The resistance patterns of gram-negative bacteria against plants are not surprising. Commonly the group of gramnegative bacteria have shown high resistance in comparison to gram-positive bacteria. This resistance pattern is due to permeability hence provided by their cell wall chemistry or by the membrane accumulation mechanism ${ }^{1}$. In this study, the ratio of Salmonella was slightly inhibited by the activity of orange extracts. Such results are very interesting and can be related to previous studies in which concentrated extracts produce more bacterial inhibition. The bioactive compounds of citrus peels can kill pathogenic bacteria using different mechanism and have high therapeutic value as an antibacterial agent against a number of multi-drug resistant bacterial populations. The extent of variation in the sensitive pattern of the Gram-negative bacteria and Gram-positive bacteria is because of their cell wall composition or its chemistry. Gram-positive bacterial cell wall is the permeable due to presence of peptidoglycan as their outer cell layer on the other side gram-negative bacteria have high lipid content ${ }^{10}$. Result plotted from the above research study provides the effective scientific basis for the use of methanol extract of Citrus sinesis and Citrus limon as antibacterial agent. This citrus fruit peel extract against the foodborne pathogen reveals them as better inhibitory agents than synthetic compounds. However, a number of studies have been required to screen the active constituent of these fruit peels with their pharmacology benefits. Studies on citrus fruit peels are necessary to determine their active constituent activity ${ }^{11}$. The inhibitory effect of these extracts can be enhanced by the purification of the bioactive compounds and also measurable doses design for the administration.

\section{Statistical Analysis}

All the data obtained from secondary screening was analyzed by one-way ANOVA. The level of significance was determined using SPSS version 15 and the results having a $P$ value $<0.05$ were defined to be significant.

\section{REFERENCES}

1. Abu-shanab B, Adwan G, Abu-safiya D, Jarrar N Adwan K. Antibacterial Activities of Some Plant Extracts Utilized in Popular Medicine in Palestine. Turk J Biol. 2004; 28: 99-102.

2. Gislene GF, Locatelli NJ, Paulo CF. Giuliana LS. Antibacterial activity of plant extracts and phytochemicals on antibiotic-resistant bacteria. Braz J Microbial. 2000; 31: 247-56

3. Kirbaslar GF, Tavman A, Dulger B, Turker G. Antimicrobial activity of Turkish citrus peel oil. Pak J Bot 2009; 41(6): 3207-12.

4. Ortuno AA, Baidez P, Gomez MC, Arcas I, Porras AG, Del Rio J.A. Citrus paradisi and Citrus sinensis flavonoid: Their influence on the defense mechanism against Penicillium digitatum. Food Chem 2006; 98(2): 351-8.

5. Seenivasan P, Manickkam J, Savarimuthu I. In vitro antibacterial activity of some plant essential oils. BMC Complem Altern. M2006 ;6: 39

6. Burt SA. Essential oils: Their antibacterial properties and potential applications in foods: A review. Inter. J Food Microbiol 2004; 94: 223-53.

7. Sohn HY, Son KH, Know CS, Kang SS. Antimicrobial and cytotoxic activity of 18 prenylated flavonoids isolated from medicinal plants: Morus alba L., Morusmongolica Schneider, Broussonetia Papyrifera (L.) Vent, Sophora flavescens Ait and Echino sophora koreensis Nakai. Phytomed. 2004; 11: 666672.

8. Jannatun T. Demonstration of Anti-Bacterial Activity of commonly available Fruit Extractsin Dhaka, Bangladesh. Amer J Microbiol Research 2014; 68-73.

9. Ghouri M, Afshan N, Javed S, Fatima A, Sadat A, Chohan A, Nadeem S.G. Physiochemical evaluation and liability of dromedary camels milk in combating various pathogens. Afri J Microbiol Res 2016; (17): 39-45.

10. Malanovic N, Lohner K. Gram-positive bacterial cell envelopes: The impact on the activity of antimicrobial peptides. Biochimica et Biophysica Acta (BBA)Biomembranes. 2016; 936-46.

11. Gyawali R, Salam A. Natural products as antimicrobial agents. Food Cont 2014; 412-29. 